\title{
ESTIMATION OF JOINT AND INTERFACE PARAMETERS FOR THE FINITE ELEMENT ANALYSIS OF JOINTED CONCRETE PAVEMENT USING STRUCTURAL EVALUATION RESULTS
}

Swati Roy Maitra, Scientist, Civil Engineering Department, Indian Institute of Technology, Kharagpur, Pin 721 302, West Bengal, India, Email: swati@ civil.iitkgp.ernet.in

K. S. Reddy, Professor, Civil Engineering Department, Indian Institute of Technology, Kharagpur, Pin 721 302, West Bengal, India, Email: ksreddy@ civil.iitkgp.ernet.in

L. S. Ramachandra, Professor, Civil Engineering Department, Indian Institute of Technology, Kharagpur, Pin 721 302, West Bengal, India, Email: $\underline{\text { lsr@ civil.iitkgp.ernet.in }}$

doi: 10.1515/ijpeat-2015-0007

\begin{abstract}
In the analysis of jointed concrete pavement, it is necessary to appropriately model certain aspects of the pavement for accurate estimation of its structural responses. These include load transfer at joints (doweled and aggregate interlocked) and interface condition between slab and foundation. This paper presents a backcalculation method for estimating the joint parameters, both transverse and longitudinal, and the interface parameter along with the pavement layer moduli by using the results of structural evaluation of an in-service concrete pavement. The details of the structural evaluation using Falling Weight Deflectometer (FWD) and the two-stage backcalculation procedure using a three-dimensional finite element (FE) model for jointed concrete pavement are discussed. Modulus of dowel support and modulus of interlocking joints are the transverse and longitudinal joint parameters respectively and the coefficient of friction between concrete slab and foundation is the interface parameter considered for the analysis. These parameters are the useful inputs in modeling jointed concrete pavement using finite element method.
\end{abstract}

Keywords: Concrete pavement, Joint parameters, Interface parameter, Backcalculation, Structural evaluation, Finite element method

\section{INTRODUCTION}

For the design and analysis of jointed concrete pavements, it is essential to have an understanding of its characteristics and responses under different loads. Joints are the elements in concrete pavements which transfer the applied wheel loads to the adjacent panels. Mainly two mechanisms are responsible for load transfer: dowel bar system for heavily trafficked roads with larger joint spacing and aggregate interlocking mechanism for lighter trafficked roads with shorter joint spacing.

For the effective functioning of the transverse and longitudinal joints, certain parameters are responsible. For doweled joints, the load transfer depends upon diameter, length and spacing of dowels, looseness of dowels, modulus of dowel support, concrete slab thickness, joint opening, and properties of concrete and subgrade (Guo et al., 1995; Davids et al., 2003; Maitra et al., 2009b). The interaction 
between concrete and steel dowels, generally termed as modulus of dowel support, plays an important role in the load transfer mechanism of a jointed concrete pavement (Yoder and Witczak 1975). For an aggregate interlocked joint, the load transfer depends upon width of crack/joint opening, aggregate characteristics like type, size and strength, nature of the cracked face, slab thickness, and subgrade strength (Colley and Humphrey, 1967). The strength of the cracked face, expressed as modulus of interlocking joints (Maitra et al., 2010), influences significantly the load transfer through aggregate interlocking. The modulus of dowel support $(K)$ and the modulus of interlocking joints $\left(K_{j}\right)$ are termed in this work as joint parameters for doweled and aggregate interlocked joints respectively. The bonded or unbonded interface characteristics between concrete slab and foundation also influence the load transfer. The coefficient of friction $(\mu)$, which denotes the interface condition between concrete slab and the base (Maitra et al., 2009a), is termed as interface parameter in this work. The joint and interface parameters are considered to be useful inputs for the analysis of concrete pavement using finite element method. In this paper, these joint and interface parameters are estimated by a two-stage backcalculation procedure using the results of structural evaluation of an in-service concrete pavement on the national highway in India.

This paper presents the details of the two-stage backcalculation procedure adopted to estimate the joint and interface parameters. In the first stage, using interior load case data, elastic moduli of all the pavement layers and the modulus of subgrade reaction of the subgrade were backcalculated. In the second stage, corner loading deflection measurement data were used along with the layer parameters, estimated from stage one, to backcalculate the joint and interface parameters $\left(K, K_{j}\right.$ and $\left.\mu\right)$. The approach for the backcalculation of these parameters was illustrated using FWD deflection data collected for different load positions from a study conducted on an in-service concrete pavement. The finite element model, using the calibrated joint and interface parameters, was validated using additional FWD deflection data.

\section{REVIEW OF LITERATURE}

For the structural evaluation of pavements, several non-destructive techniques are available of which the application of FWD loading is the most popular. In this method, an impulse load is applied on the pavement and the resulting surface deflections are measured directly under the load and also at certain distances away. The modulus values of the concrete slab, base layers and the supporting subgrade are generally backcalculated using the deflection values measured at different locations on the pavement. The efficiency of the joints can also be estimated from the deflection values taken at both sides of the joints using FWD.

Barenberg and Petros (1991) were among the first in presenting a detailed report on the application of FWD in evaluating concrete pavements, interpretation of FWD results and the backculation of pavement layer moduli values for slab of known thickness. Void detection and joint evaluation techniques were also discussed. Tang (1993) presented a methodology for evaluating the structural condition of jointed airfield concrete pavement by conducting FWD tests on a specially prepared concrete test pavement consisting of six slabs. Based on the FWD test results, the resilient modulus of foundation, load transfer efficiency of joints and the size of voids beneath the slab were detected using a finite element model. Test results and FE results 
showed that there was no one-to-one correlation between the deflection efficiency and the stress efficiency. Shuo et al. (1997) developed an analytical closed-form backcalculation program for estimating the layer moduli for a two-layer pavement system. The method gave a unique solution for the backcalculated parameters.

Crovetti (2002) presented a technique for analyzing deflection data obtained at slab center, edge and corner to estimate the quality and uniformity of support beneath the jointed concrete slabs considering slab size and curling efffect. Ioannides et al. (2005) determined the in-situ joint effectiveness values for concrete pavement using dimensional analysis applying artificial neural network. It was demonstrated that dimensional analysis reduced the number of variables to be used and thereby could broaden the range of applicability of the neural network algorithm. Fwa and Setiadji (2006) evaluated and compared several backcalculation algorithms in estimating the pavement slab elastic modulus and the modulus of subgrade reaction for nondestructive determination of concrete pavement properties. The authors concluded that the choice of sensor configurations, i.e., the number of sensors and their locations, affects the performance of the backcalculation algorithms. Lin et al. (2006) used a rapid and portable FWD for pavement evaluation and concluded that the size of the loading plate is an important consideration while the effect of drop height is insignificant in estimating the pavement layer moduli. Kanta Rao et al. (2006) evaluated in-service concrete pavements using FWD and Ultrasonic Pulse Velocity (UPV) technique and found that the two compared well. The authors suggested a methodology to estimate the structural parameters of uncracked pavement slabs from the dynamic modulus of elasticity obtained from UPV.

The backcalculation algorithms are mostly based on static linear elastic theory, though the applied load in FWD is actually an impulse load (Shoukry and William, 1999). The performance of various static and dynamic backcalculation algorithms were evaluated by several researchers (Shoukry and William, 1999; Ameri et al., 2009). Shoukry and William, (1999) used a three-dimensional FE model to estimate the dynamic moduli of pavement layers for rigid, flexible and composite pavements taking into account the dynamic nature of FWD load, interlayer friction and geometric characteristics of pavement structure. Correction factors were suggested to estimate the dynamic layer moduli values from their corresponding static values obtained from the static backcalculation algorithms.

Chatti and Kim (2001) presented a dynamic backcalculation procedure to estimate the dynamic subgrade stiffness and damping coefficients from FWD results which was verified with field data. The method was also used to detect the presence of any stiff layer underneath the pavement system. Picoux et al. (2009) used a finite element model to predict the dynamic behavior of flexible pavement subjected to an impulse load. The responses were validated with the results of a real pavement subjected to dynamic loads obtained from FWD testing.

FWD can also be used to determine the condition of the joints by evaluating its load transfer efficiency. Deflections of the loaded and unloaded slabs were measured using FWD, with the loading plate and the sensor below it on one slab while the other sensors were on the adjacent slab. Based on the deflection values, the performance of the joint was estimated. Permissible deflection values of pavement slab at their joints for adequate load transfer were suggested by different researchers. Zube and Forsynth 
(1966) obtained the maximum tolerable deflection of a concrete pavement of $200 \mathrm{~mm}$ thickness under a load of $68 \mathrm{kN}$ as $0.30 \mathrm{~mm}$. Christory (1988) suggested tolerable deflections for concrete pavements, laid on stabilized and unstabilized bases. For stablized bases, a deflection value of less than $0.20 \mathrm{~mm}$ was considered satisfactory by the authors (Christory, 1988). The Indian Roads Congress (IRC: 58 - 2011) stated that the maximum deflection for jointed concrete pavement to be about $1.25 \mathrm{~mm}$. This criterion, considering the effects of local conditions, was actually used for estimating the modulus of subgrade reaction, but could also be applicable for estimating the pavement layer moduli as well.

It is found from the literature that though the existing backcalculation algorithms are efficient in estimating the pavement layer moduli and also to estimate the load transfer efficiency of the joint, they do not account for the joint load transfer parameters like modulus of dowel support and modulus of interlocking joints and also the interface parameter like coefficient of friction, which are useful inputs for the analysis of jointed concrete pavement using finite element method. This paper presents a twostage backcalculation procedure to estimate the joint and interface parameters. The details of the two-stage backcalculation procedure are given in the following sections.

\section{BACKCALCULATION OF PAVEMENT LAYER PARAMETERS, JOINT PARAMETERS AND INTERFACE PARAMETER}

Structural evaluation of a newly-constructed concrete pavement has been carried out in this study. FWD tests were conducted on some concrete slabs of an in-service national highway (NH60) in the eastern part of India. Responses of the pavement sections were measured in terms of surface deflections for different load positions interior, corner, and edge and also at the joints. The data collected from field investigation were used in the $1^{\text {st }}$ stage of backcalculation to estimate the pavement layer parameters (elastic moduli values of different pavement layers) and the modulus of subgrade reaction. These pavement layer parameters were then utilized for the $2^{\text {nd }}$ stage of backcalculation of joint and interface parameters. Details of the structural evaluation program and the two-stage backcalculation of different pavement layer parameters, joint parameters and interface parameter are presented in the following sections.

\section{Structural evaluation of in-Service concrete pavement}

A stretch of pavement was selected for structural evaluation purpose using an indigenously developed FWD. The details of the test sections, the salient features of the FWD and the test program are discussed in subsequent sections.

\section{Details of Test Sections}

The experimental stretch considered for investigation is a part of the $120 \mathrm{~km}$ long section of national highway (NH60) from Kharagpur in the state of West Bengal to Balasore in Orissa, construction of which was completed in the year 2003 (using slipform paving technology). The road was opened for traffic in the year 2004. The fourlane divided carriageway road has $3.5 \mathrm{~m}$ wide lanes (two in each direction) with the width of the median being $9.0 \mathrm{~m}$. Each two-lane carriageway has $1.5 \mathrm{~m}$ wide paved (concrete) shoulder. Transverse (contraction) joints are provided at $4.5 \mathrm{~m}$ spacing. There are longitudinal joints between the traffic lanes and between the outer traffic lane and the shoulder. These joints are formed by saw-cutting the concrete slab up to 
one-third of its depth (IRC: 58, 2011). The pavement has $300 \mathrm{~mm}$ thick plain cement concrete (PCC) slab laid over $150 \mathrm{~mm}$ thick dry lean concrete (DLC) base, which, in turn, is placed over $150 \mathrm{~mm}$ thick granular subbase (GSB). A separation membrane, 125 micron thick impermeable polythene sheet, is provided between the concrete slab and the DLC layer to make the interface unbonded or smooth. The interface between DLC and GSB is however made as bonded or rough interface as the DLC is placed directly over the GSB. The pavement has $500 \mathrm{~mm}$ thick prepared (compacted) subgrade below the subbase. Mild steel round dowel bars of $32 \mathrm{~mm}$ diameter and 600 $\mathrm{mm}$ in length, placed at $400 \mathrm{~mm}$ centre to centre, are used across the transverse joints at the mid-depth of the concrete slab for load transfer. On one side of the joint, the dowel bars are covered by a hard plastic sheet of $1.25 \mathrm{~mm}$ thickness. Tie bars of 16 $\mathrm{mm}$ diameter and $800 \mathrm{~mm}$ in length are placed at a spacing of $1060 \mathrm{~mm}$ center to centre across the longitudinal joints to hold the slab panels in their positions. A schematic detail of the pavement stretch is shown in Figure 1.

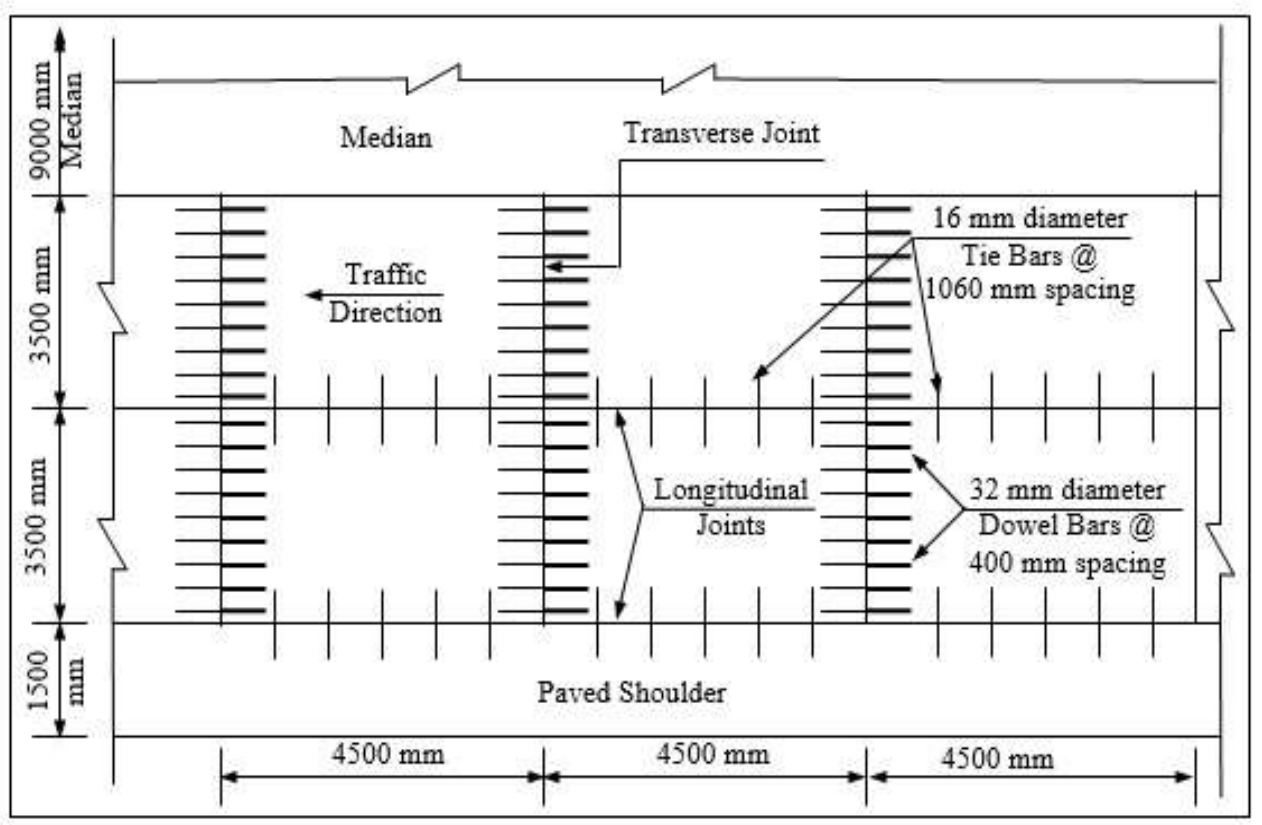

Figure 1. Schematic details of test sections

\section{IIT Kharagpur FWD}

A FWD, developed and fabricated in the Transportation Engineering Section of the Civil Engineering Department of IIT Kharagpur, India (Reddy et al., 2003), was used for the structural evaluation of the pavement sections. The indigenous IIT Kharagpur FWD consists of the FWD equipment fitted inside a vehicle with a data acquisition system. A steel plate of $300 \mathrm{~mm}$ diameter is used for applying the load on the pavement surface. The mass is dropped on a system of circular rubber pads from a suitable height. Rubber pads are used to damp out the vibration of the FWD while dropping the load. The equipment has the facility to vary both the mass and the falling height for applying the impulse load. Loading time is controlled through the selection of appropriate stiffness of rubber pads. Six rubber pads are used to produce pulse duration in the range of 20 to 30 milliseconds. This corresponds to the loading time produced by a truck running at a speed of $65-80 \mathrm{~km} / \mathrm{hour}$. The impulse load history is recorded with the help of a load cell of $100 \mathrm{kN}$ capacity. The surface of the pavement deflects under the application of the impulse load in the form of a bowl. Geophones, arranged on a geophone frame at radial distances of 0, 300, 600, 900, 
1200,1500 and $1800 \mathrm{~mm}$ from the centre of the loading plate, are used to measure the surface deflections at these locations. The load and the deflection data are stored by a data acquisition system.

\section{FWD Test Program}

Falling Weight Deflectometer tests were carried out on the selected concrete pavement sections of national highway. A number of concrete pavement panels, free from any visible cracks and other distresses, were selected for the purpose of structural evaluation. The evaluation was performed in February, 2009. The tests involved measurement of surface deflections at different locations under the application of an impulse type load. Before testing, the load cell and all the seven geophones were calibrated using a proving ring and a vibration meter respectively.

Load was applied at different locations of the selected slab panels and deflections were recorded. The load positions and the corresponding locations, at which the deflections were measured, are detailed below and are also schematically shown in Figure 2.

- Location 1: Load at the interior of the slab panel

- Location 2: Load at the transverse edge of the slab panel with all geophones on the same panel

- Location 3: Load at the corner of the slab panel

- Location 4: Load at the longitudinal edge of the slab panel

- Location 5: Load at the transverse joint edge of the slab panel with all but the central geophone on the adjacent panel

- Location 6: Load at the longitudinal joint edge on the shoulder with all but the central geophone on the slab (outer lane)

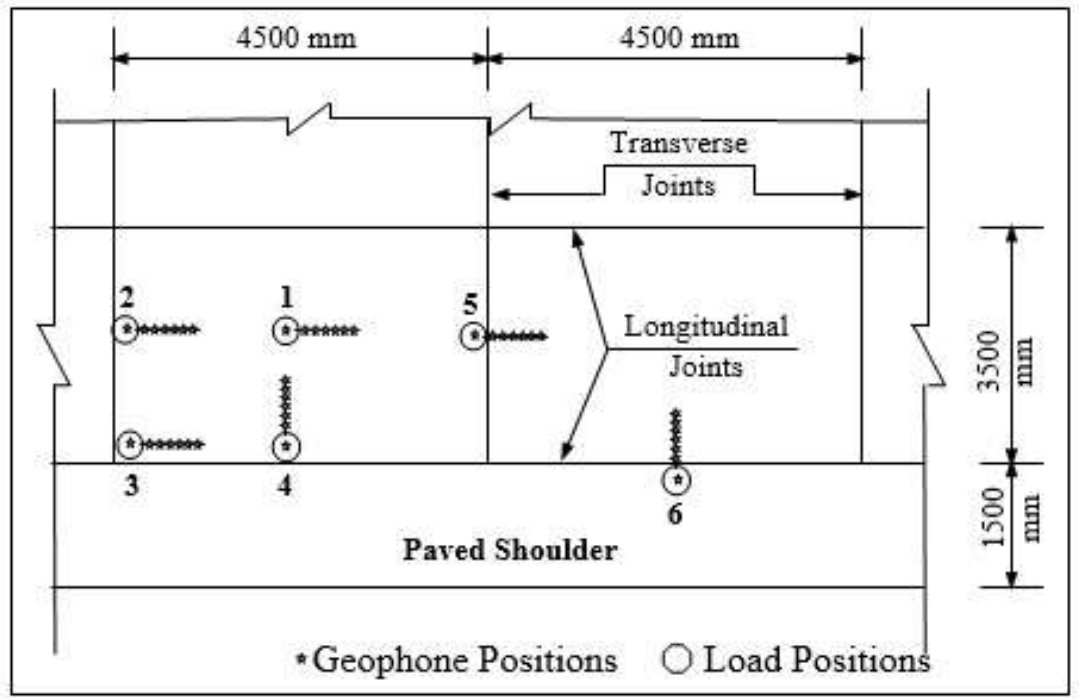

Figure 2. Typical locations selected for FWD testing

Locations ' 1 ', '2' and ' 3 ' corresponded to interior, edge (transverse) and corner load positions. Position ' 4 ' was selected for applying the load near the longitudinal edge (away from the transverse edges). Positions ' 5 ' and ' 6 ' were considered for evaluating 
the condition of the transverse and longitudinal (between traffic lane and shoulder) joints. For these two cases, the load plate and the central geophone were placed on one side of the joint whereas the remaining geophones were positioned on the other side of the joint. Figure 3 shows a view of the structural evaluation of the concrete pavement using the in-vehicle FWD.

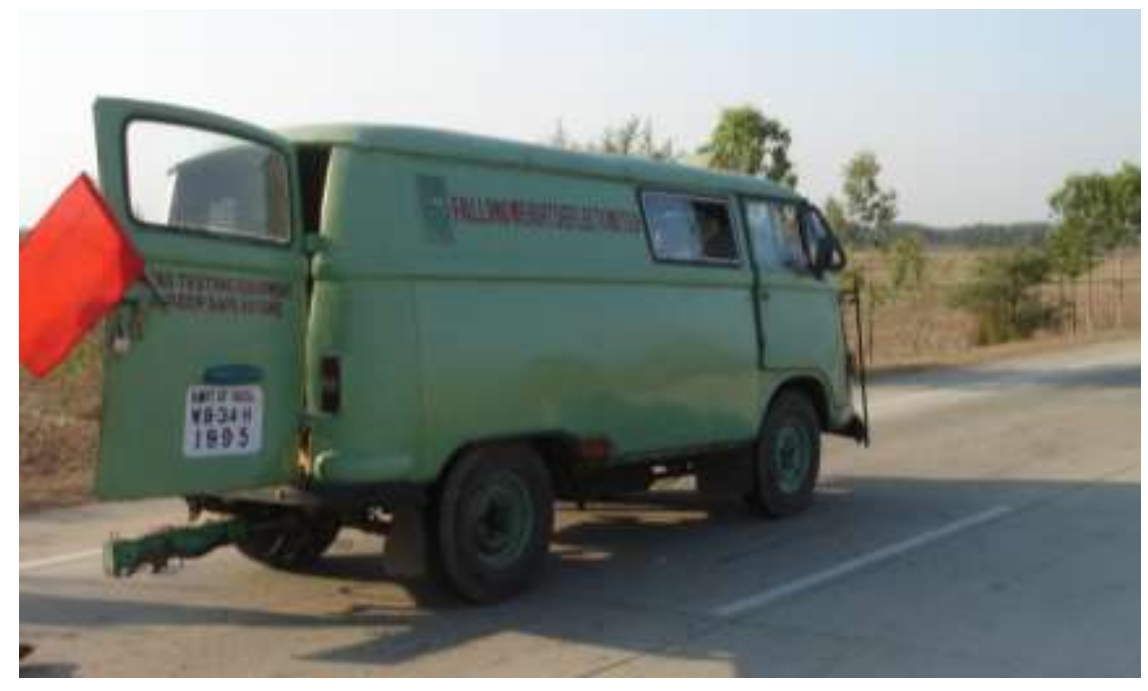

Figure 3. Field evaluation of concrete pavement using FWD

\section{Results of FWD test}

In the FWD tests, the measured deflections due to different impulse loads were obtained from few different but similar slab panels. At least three sets of deflection data were recorded for each slab panel. The deflections measured from FWD tests were normalized for a standard wheel load of $41 \mathrm{kN}$. Under the normalized wheel load of $41 \mathrm{kN}$, the range of the maximum surface deflections at the interior, corner and edge of the slab panels are given in Table 1. For the newly-constructed pavement, the deflection values are found to be well within the tolerable deflection values as recommended by the available literature (Zube and Forsynth, 1966; Christory, 1988; Kanta Rao et al., 2006).

Table 1. Range of maximum surface deflections obtained from FWD tests for the normalized wheel load of $41 \mathrm{kN}$

\begin{tabular}{|c|c|}
\hline Load Position & Surface Deflections \\
\hline Interior & 0.078 to $0.100 \mathrm{~mm}$ \\
\hline Corner & 0.093 to $0.143 \mathrm{~mm}$ \\
\hline Edge & 0.082 to $0.138 \mathrm{~mm}$ \\
\hline
\end{tabular}

\section{Finite element analysis of the pavement stretch}

The in-service concrete pavement section on the national highway used for the structural evaluation was analyzed with the help of a comprehensive threedimensional finite element model. The numerical model developed by Maitra et al., (2009a, 2009b and 2010) was considered for this purpose. The pavement stretch as shown schematically in Figure 1 was modeled and the finite element representation of the same is shown in Figure 4, drawn in ANSYS software (ANSYS Inc., Cannonsburg, PA, 2002). The FWD tests were conducted only on the outer traffic lane of the pavement stretch. Hence, two panels of the outer traffic lane, along with the corresponding paved shoulder portions, were considered for finite element 
representation. The panels of the inner traffic lane (adjacent to median) were not considered for FE analysis since these panels had no significant influence on the responses of the pavement for the loading conditions adopted during field investigation. As shown in the figure, the FE model included two slab panels each of $3.50 \mathrm{~m}$ width with $1.50 \mathrm{~m}$ wide paved shoulder on one side. The $300 \mathrm{~mm}$ thick PCC slab panels were supported on foundation comprised of $150 \mathrm{~mm}$ thick DLC and 150 mm thick GSB over compacted subgrade. Transverse and longitudinal joints were also modeled and are shown in the figure.

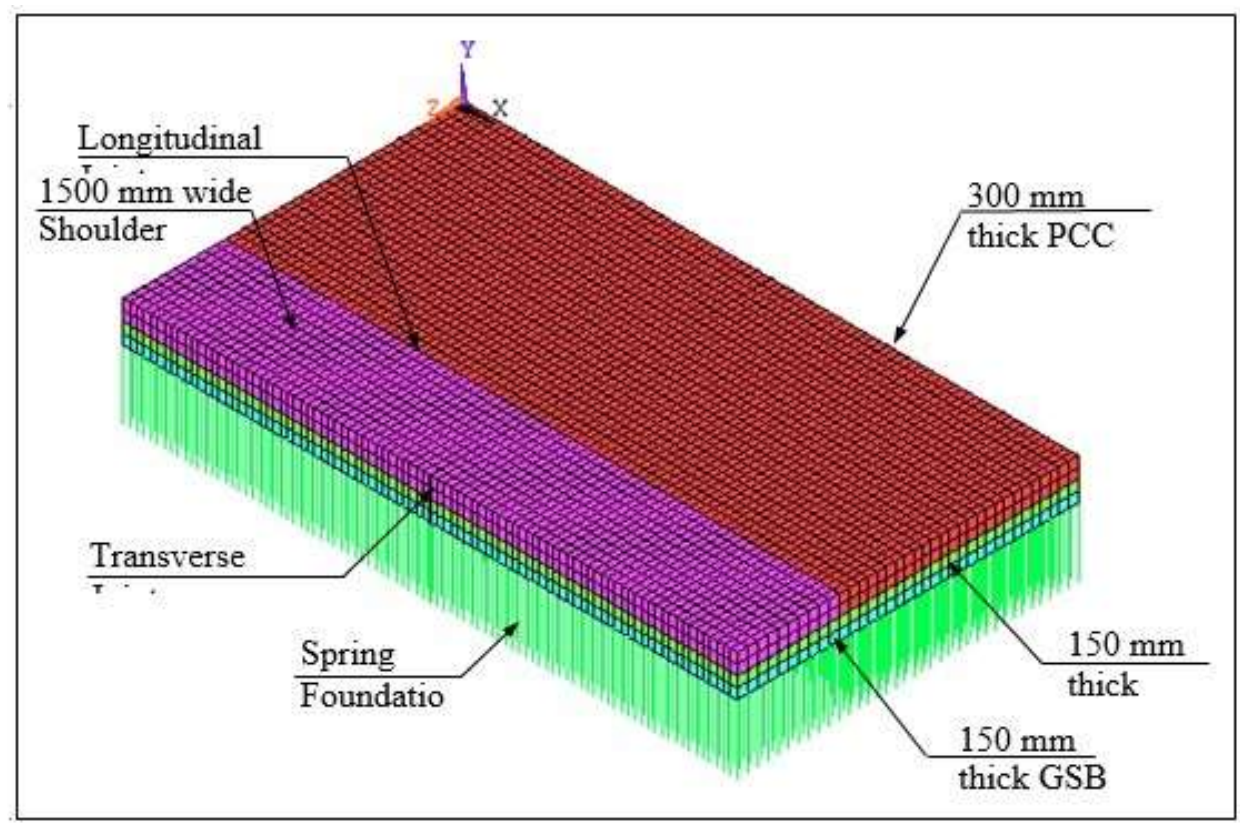

Figure 4. Finite element representation of the test section

In the FE analysis, concrete slab (along with the paved shoulder), DLC and GSB were modeled as linear elastic and isotropic materials. Eight-noded solid brick elements (SOLID45) were used to model these layers. The subgrade was modeled as Winkler foundation (Westergaard, 1926). In the Winkler model, the foundation was assumed to be composed of a bed of closely-spaced independent linear springs. Two-noded linear spring elements (COMBIN14), available in ANSYS software, were adopted to model the Winkler foundation. The effective normal stiffness of the spring element was obtained by multiplying the modulus of subgrade reaction $(k)$ with the influencing area of that element.

The unbonded interface between PCC slab and DLC base was modeled using contact elements (CONTA178) to represent the effect of plastic sheet (Maitra et al., 2009a). These two-noded contact elements could represent contact as well as sliding between any two surfaces by supporting only compression in the contact normal direction and frictional force in the tangential direction. The interface coefficient of friction $(\mu)$ was the only material property required for this element.

Dowel bars were modeled as beam elements (BEAM4) (Maitra et al., 2009b). To represent the capped portion of the dowel bar covered with plastic sheet at one side of the joint, the beam elements were connected to the solid brick elements of concrete slab by a series of zero-length contact elements (CONTA178). The interaction between dowel and concrete, usually denoted by modulus of dowel support $(K)$, was 
represented by these contact elements (Maitra et al., 2009b). The normal stiffness of this element was estimated by multiplying the modulus of dowel support value with the effective bearing area of the corresponding dowel. The uncapped portion of the dowel bar was modeled by connecting the beam elements directly with the solid brick elements of the concrete slab. Since there was no available data and the pavement was newly constructed, it was assumed that the dowel bars were perfectly aligned without having any looseness around them.

Along the longitudinal joint, the applied load was assumed to transfer through aggregate interlocking mechanism. Tie bars are provided along the longitudinal joints to hold the slab panels in their positions. The main function of the tie bars is to keep the joint from opening wide, so that the aggregate interlocking is not reduced. Significantly, the tie bars by themselves, do not directly contribute much to load transfer. In this work, aggregate interlock was modeled using two series of linear spring elements (COMBIN14) connecting the slab panels with the adjacent shoulders. The spring stiffness was estimated by considering the modulus of interlocking joints $\left(K_{j}\right)$, which represented the strength characteristics of the cracked face (Maitra et al., 2010). The modulus value was a function of aggregate size and crack/joint width, the two most important parameters in load transferring across these joints. The stiffness of each spring was estimated by multiplying the modulus of interlocking joints with the effective bearing area of that spring at the joint face.

Modulus of dowel support $(K)$ and modulus of interlocking joints $\left(K_{j}\right)$ were considered to be the transverse and longitudinal joint load transfer parameters respectively and the coefficient of friction $(\mu)$ between slab and base as the interface parameter for the analysis of jointed concrete pavement.

FWD loading was simulated as an impulse type pressure load over a rectangular contact area of size $300 \mathrm{~mm} \times 266.67 \mathrm{~mm}$ (approximately the same area as that of the FWD loading plate of $300 \mathrm{~mm}$ diameter) applied for a very short time. Since the pavement was in good condition (newly constructed) and the tests were performed during the cooler season of the year, the temperature differential had little influence on FWD results (Barenberg and Petros, 1991). Therefore, the effect of temperature was not considered in the analysis.

\section{Backcalculation of pavement layer parameters}

Data pertaining to the FWD tests conducted with the load applied in the interior of the slab were used to backcalculate the elastic moduli of the pavement layers and the modulus of subgrade reaction for the subgrade. These properties were backcalculated by assigning typical values to the joint parameters (modulus of dowel support and modulus of interlocking joints), since interior deflections are not significantly influenced by the joint parameters. In the process of backcalculation, dynamic analysis was performed as the FWD load was actually dynamic in nature (Picoux et al., 2009). Latest literature on this indicated that static backcalculation procedure is likely to give overestimated values of the pavement parameters (Shoukry and William, 1999; Chatti and Kim, 2001). The FE model considered for the present analysis was validated for dynamic loading by comparing the responses of a flexible pavement under impulse loading reported by Picoux et al. (2009). In the present dynamic analysis, damping effect was neglected. 
For backcalculating the pavement parameters from interior load case data, different sets of pavement parameters (elastic moduli, Poisson's ratio and density of PCC, DLC and GSB and modulus of subgrade reaction for subgrade) were selected. Typical values were also assigned to joint and interface parameters. For the doweled joint, the $K$ value was selected based on the earlier studies by different researchers (Guo et al. 1995; Bhattacharya, 2000, Maitra et al., 2009b). For the aggregate interlocked joint, $K_{j}$ value was selected based on the guidelines suggested by Maitra et al. (2010) considering a crack width of $0.6 \mathrm{~mm}$ and maximum aggregate size as $20 \mathrm{~mm}$ for the PCC slab. For the unbonded interface between slab and DLC base, $\mu$ value was selected based on the Push-off test results recommended by Maitra et al. (2009a). The assigned values considered for the $1^{\text {st }}$ stage backcalculation procedure are given in Table 2.

Table 2. Assigned values for pavement layer moduli, modulus of subgrade reaction, joint and interface parameters for $1^{\text {st }}$ stage backcalculation

\begin{tabular}{|c|c|c|}
\hline $\begin{array}{c}\text { Pavement Layers } \\
\text { Joints }\end{array}$ & Layer / Joint Parameters & Assigned Values \\
\hline \multirow{3}{*}{ PCC } & Elastic Modulus, $E(\mathrm{MPa})$ & 25,000 to 46,000 \\
\hline \multirow{3}{*}{ DLC } & Poisson's ratio, $v$ & 0.15 \\
\cline { 2 - 3 } & Density, $\left(\mathrm{kg} / \mathrm{m}^{3}\right)$ & 2400 \\
\cline { 2 - 3 } & Elastic Modulus, $E(\mathrm{MPa})$ & 15,000 to 25,000 \\
\cline { 2 - 3 } & Poisson's ratio, $v$ & 0.15 \\
\cline { 2 - 3 } GSB & Density $\left(\mathrm{kg} / \mathrm{m}^{3}\right)$ & 2000 \\
\cline { 2 - 3 } & Elastic Modulus, $E(\mathrm{MPa})$ & 250 to 1000 \\
\cline { 2 - 3 } & Poisson's ratio, $v$ & 0.35 \\
\hline Subgrade & Density $\left(\mathrm{kg} / \mathrm{m}^{3}\right)$ & 1700 \\
\hline Steel & Modulus of Subgrade Reaction, $k(\mathrm{MPa} / \mathrm{mm})$ & $2.0 \times 10^{5}$ \\
& Elastic Modulus, $E(\mathrm{MPa})$ & 0.30 \\
\hline Transverse Joint & Poisson's ratio, $v$ & $407 \times 10^{6}$ \\
\hline Longitudinal Joint & Modulus of dowel support, $K\left(\mathrm{kN} / \mathrm{m}^{3}\right)$ & 5 \\
\hline Slab-base Interface & Modulus of interlocking joints, $K(\mathrm{MPa} / \mathrm{mm})$ & 0.75 \\
\hline
\end{tabular}

Backcalculation was carried out iteratively by adjusting the pavement parameter values (elastic moduli of different layers and modulus of subgrade reaction for subgrade) to get an acceptable match between the computed and the measured deflection basins. Figure 5 shows the comparison of the computed and the measured deflection basins for interior loading condition. The measured deflections were obtained from two different but similar slab panels. The backcalculated dynamic moduli for PCC, DLC and GSB layers and the modulus of subgrade reaction are given in Table 3.

Table 3. Pavement layer moduli and modulus of subgrade reaction obtained from $1^{\text {st }}$ stage backcalculation

\begin{tabular}{|l|l|l|}
\hline $\begin{array}{l}\text { Pavement } \\
\text { Layers }\end{array}$ & Layer Parameters & $\begin{array}{l}\text { Backcalculated } \\
\text { Values }\end{array}$ \\
\hline PCC & Elastic Modulus, $E(\mathrm{MPa})$ & 44,875 \\
\hline DLC & Elastic Modulus, $E(\mathrm{MPa})$ & 22,000 \\
\hline GSB & Elastic Modulus, $E(\mathrm{MPa})$ & 1000 \\
\hline Subgrade & $\begin{array}{l}\text { Modulus of Subgrade Reaction, k } \\
(\mathrm{MPa} / \mathrm{mm})\end{array}$ & 0.35 \\
\hline
\end{tabular}

However, for design purposes, static moduli values are normally considered. The static moduli values are generally smaller than their corresponding dynamic values. In 
case of PCC, empirical relationships are available in the literature (Neville and Brookes, 1987; Choudhuri et al., 2002; Gambhir, 2004) for estimation of static modulus value from its dynamic modulus. AASHTO (1993) recommends a multiplying factor of 0.5 for obtaining the static modulus of subgrade reaction from the corresponding dynamic value using FWD evaluation.

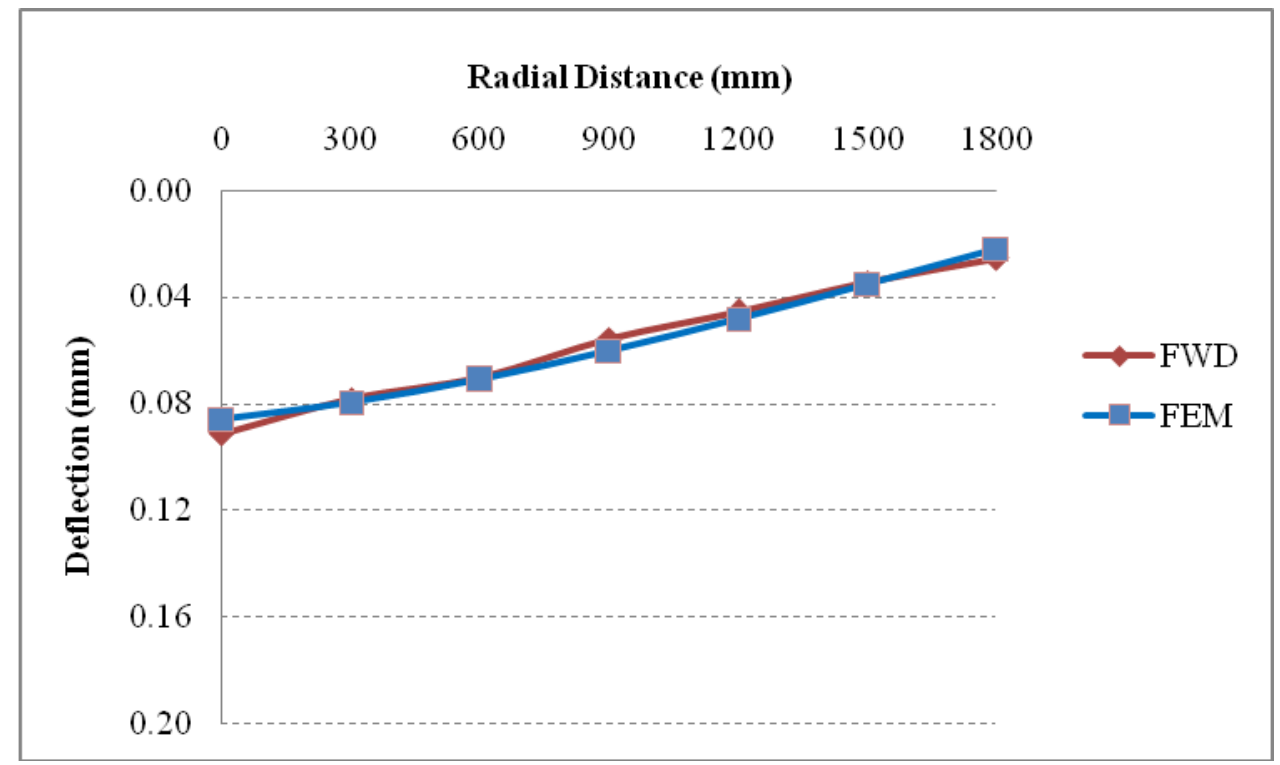

Figure 5. Comparison between experimental and finite element deflection basins for interior loading condition

\section{Backcalculation of joint parameters}

The pavement layer parameters, backcalculated from the deflection data collected for interior load case, were used for the next stage of backcalculation, in which load transfer parameters and interface parameter were evaluated from corner loading condition. A range of values were assigned to joint (modulus of dowel support and modulus of interlocking joints) and interface parameters (coefficient of friction) for the $2^{\text {nd }}$ stage of the backcalculation procedure. The assigned values for these parameters are given in Table 4.

Table 4. Assigned range of values for joint and interface parameters for $2^{\text {nd }}$ stage backcalculation

\begin{tabular}{|c|c|c|}
\hline Joint / Interface & Joint / Interface Parameters & Assigned Values \\
\hline Transverse Joint & $\begin{array}{c}\text { Modulus of Dowel Support, } K \\
(\mathrm{MPa} / \mathrm{mm})\end{array}$ & 400 to 650 \\
\hline Longitudinal Joint & $\begin{array}{c}\text { Modulus of Interlocking Joints, } K_{j} \\
(\mathrm{MPa} / \mathrm{mm})\end{array}$ & 5 to 10 \\
\hline $\begin{array}{c}\text { Interface between PCC } \\
\text { \& DLC }\end{array}$ & $\begin{array}{c}\text { Coefficient of Friction, } \mu \\
0.5 \text { to } 1.2\end{array}$ \\
\hline
\end{tabular}

Using an iterative procedure, analysis was carried out by adjusting the joint and interface parameters, till an acceptable match was obtained between the measured and the computed deflection basins. The pavement layer parameters, backcalculated in the previous stage, were kept constant in this stage. Figure 6 shows the comparison between the computed and the measured deflection basins for corner loading condition. Table 5 gives the backcalculated joint and interface parameter values. 


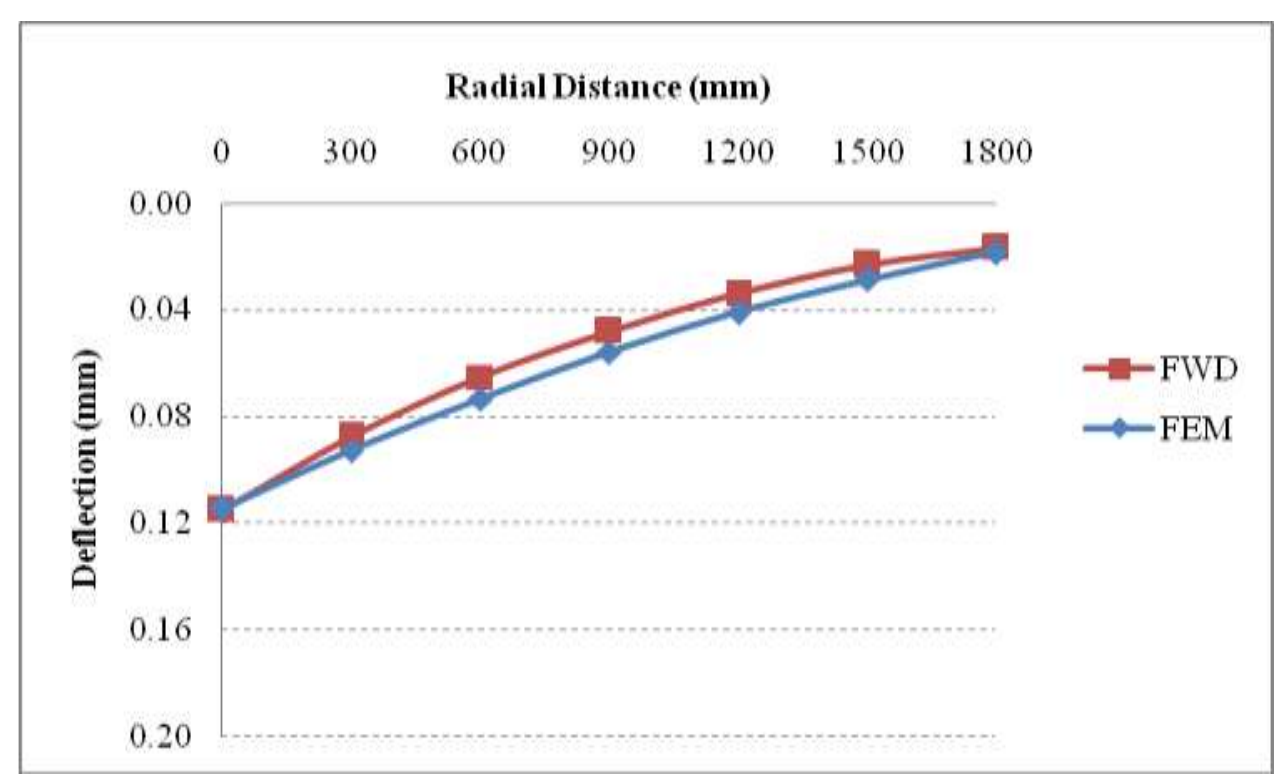

Figure 6. Comparison between experimental and finite element deflection basins for corner loading condition

Table 5. Joint and interface parameters obtained from $2^{\text {nd }}$ stage backcalculation

\begin{tabular}{|c|c|c|}
\hline Joint / Interface & Joint / Interface Parameters & $\begin{array}{c}\text { Backcalculated } \\
\text { Values }\end{array}$ \\
\hline Transverse Joint & Modulus of Dowel Support, $K(\mathrm{MPa} / \mathrm{mm})$ & 500 \\
\hline $\begin{array}{c}\text { Longitudinal Joint } \\
\text { Modulus of Interlocking Joints, } K_{j} \\
(\mathrm{MPa} / \mathrm{mm})\end{array}$ & 10 \\
\hline $\begin{array}{c}\text { Interface between PCC \& } \\
\text { DLC }\end{array}$ & $\begin{array}{c}\text { Coefficient of Friction, } \mu \\
0.75\end{array}$ \\
\hline
\end{tabular}

Figure 7 shows the flow chart for the two-stage backcalculation procedure. 


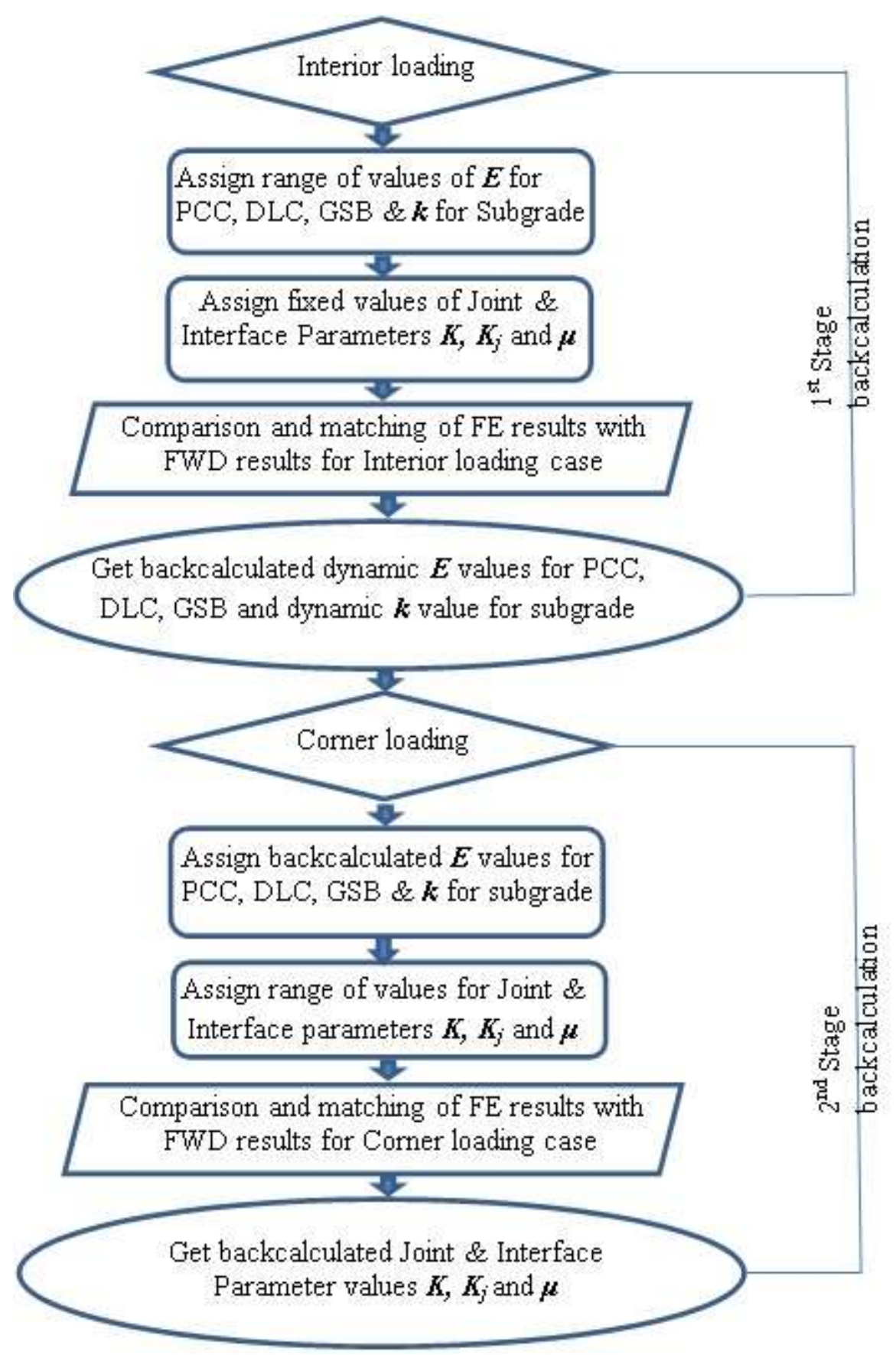

Figure 7. Flow chart for the two-stage backcalculation procedure

\section{VALIDATION OF THE BACKCALCULATION PROCEDURE}

The two-stage backcalculation procedure for estimating the joint \& interface load transfer parameters was validated by comparing the computed and the measured deflection basins for the two edge loading conditions and also by comparing the load transfer efficiencies both at the transverse and longitudinal joints.

\section{Edge load conditions}

The backcalculated pavement and joint parameters obtained from the interior and corner loading conditions were validated by comparing the deflection basins for the 
two edge loading conditions. Figures 8 and 9 show the deflection basins obtained from FWD testing and the FE analysis using the backcalculated pavement layer parameters and joint parameters for load positions ' 2 ' and ' 4 ' respectively. The measured deflections given in the figures were the average values of the three deflection data sets for the slab panel considered for the FWD test. The measured and the computed deflection basins obtained for the test sections using the backcalculated pavement layer parameters and joint parameters from the FE analysis were found to be in reasonable agreement with each other.

From the available literature, it was found that the influence of the properties of subgrade on measured deflections increased at points further away from the load point, whereas, the elastic modulus of the pavement slab had more influence on the measured deflections at points nearer to the load center (Fwa and Setiajdi, 2006). Different researchers like Li and White (2000) and Fwa and Setiajdi (2006) opined that considering deflections at locations far from the load centers in the backcalculation procedure might not be appropriate because of their very small value. In the present case, it was observed that the computed deflections for the first two geophone locations match fairly well with the measured deflections for the given load positions (with errors less than 5\%). The match of the intermediate deflections was not as good as the remaining deflections. This could be due to the possible underestimation of the actual strength achieved by the DLC layer and also the friction mobilized between the DLC layer and the slab. The actual strength of concrete achieved in the field is usually much more than the target value and the strength also increases with age.

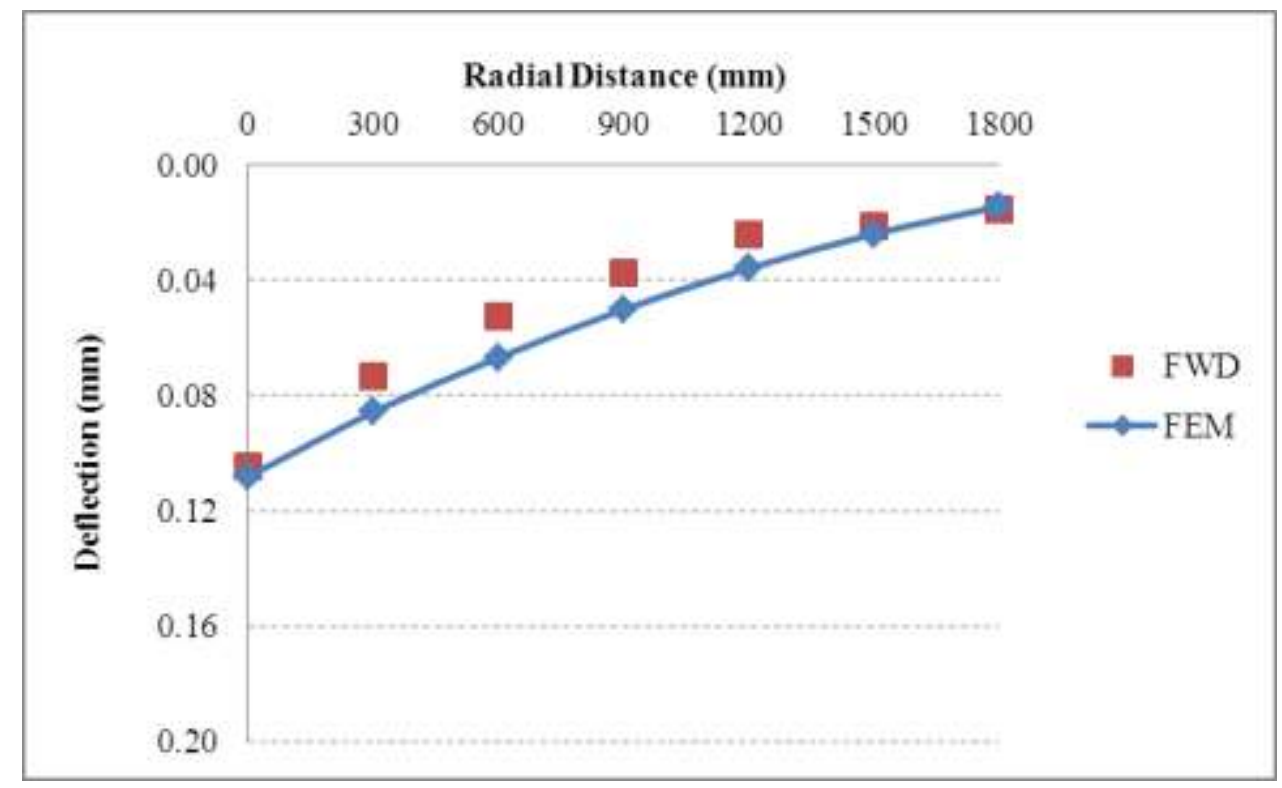

Figure 8. Comparison between experimental and finite element deflection basins for load position ' 2 ' 


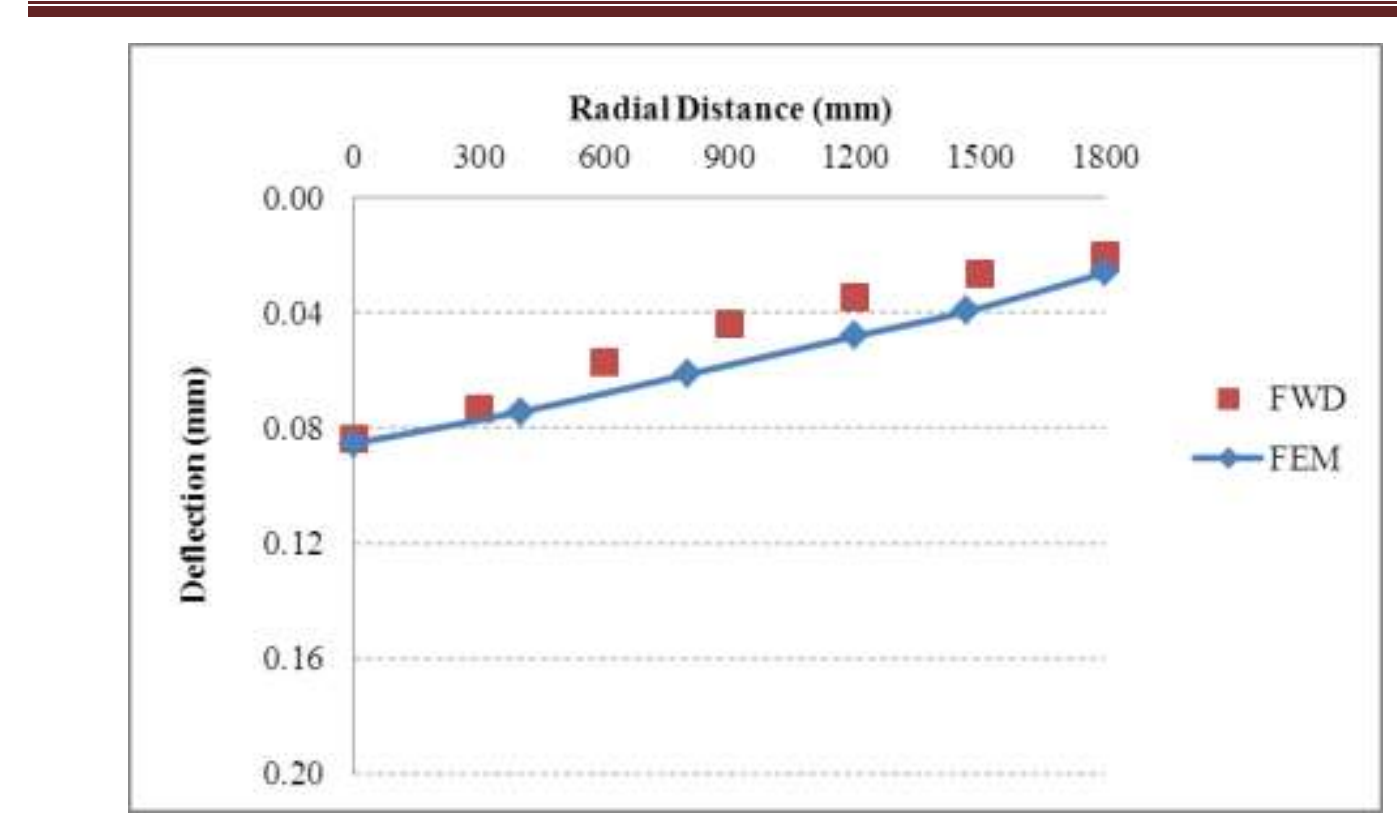

Figure 9. Comparison between experimental and finite element deflection basins for load position ' 4 '

\section{Load transfer efficiency}

The field joint load transfer efficiency (LTE) values were determined corresponding to load cases ' 5 ' and ' 6 ' for transverse and longitudinal joints respectively. The joint load transfer efficiency values for FWD testing were estimated using the relationship given by AASHTO (1993) as given in equation 1.

$$
L T E=\frac{\delta_{u l}}{\delta_{l}} \times 100 \times B
$$

Where, $B=d_{0} / d_{12}=$ slab bending correction factor and $\delta_{l}$ and $\delta_{u l}$ are respectively the deflections of the loaded and the unloaded panels of the pavement. The slab bending correction factor $(B)$ is defined as the ratio of the deflection $\left(d_{0}\right)$ just below the FWD loading plate to that measured at a distance of $300 \mathrm{~mm}$ from it, i.e., in this case at the location of the second geophone $\left(d_{12}\right)$, when the load is applied at the interior of the slab panel.

From the FWD deflection data collected from in-service concrete pavement, $B$ was calculated as 1.11 for the interior loading case. Using the factor $B$, the LTE of the transverse joint (load position ' 5 ') with dowel bar system was estimated as $90.4 \%$ and that for the longitudinal joint (load position ' 6 ') with aggregate interlocking was 93.2\%. The LTE values for these two load positions obtained from the FE analysis using the backcalculated pavement layer and joint parameters are given in Table 6 . The field LTE values and those obtained from the FE analysis were found to be in good agreement with each other. It was also observed that the efficiencies of the joints of the newly-constructed pavement were fairly good in transferring the applied load from one panel to another. Rowe et al., (1997) assessed the efficiency of joints and cracks using FWD data and suggested that the efficiency of any joint could be considered satisfactory in all respects if its LTE was found to be $75 \%$ or more. 
Table 6. Load transfer efficiencies obtained from FWD test and FE analysis

\begin{tabular}{|c|c|c|c|}
\hline \multirow{2}{*}{ Joint } & \multirow{2}{\text{Load}}{} & \multicolumn{2}{|c|}{ Load Transfer Efficiency (\%) } \\
\cline { 3 - 4 } & Position & FWD Test & FE Analysis \\
\hline Transverse & 5 & 90.4 & 91.0 \\
\hline Longitudinal & 6 & 93.2 & 95.7 \\
\hline
\end{tabular}

\section{CONCLUSIONS}

Selection of appropriate pavement parameters is essential for accurate analysis of jointed concrete pavement. Finite element models, which are often used for analysis of jointed concrete pavements, require, besides the moduli of different layers, the parameters that reflect the load transfer characteristics of joints and the interface condition between the slab and foundation.

This paper presents an approach for estimation of these parameters for any given pavement so that the same can be used in the FE model for complete analysis of the pavement. A two-stage procedure which involves structural evaluation of the concrete pavement with different load positions is recommended for this purpose which will yield joint, interface and other material parameters required for the analysis. The approach has been illustrated using FWD data collected on a national highway in India. The method has also been validated by comparing the surface deflections of the pavement computed using the estimated parameters with the measured deflections.

While the approach is a generalized one, the parameters backcalculated here are specific to the type and conditions of the pavement investigated. Future scope of this work can include estimation of different types of pavements with different combinations of layer thicknesses and strengths and different pavement conditions with possible correlation of pavement conditions to the joint and interface parameters.

\section{REFERENCES}

AASHTO (1993). "Guide for Design of Pavement Structures." American Association of State Highway and Transportation Officials.

Ameri, M., Yavari, N. and Scullion, T. (2009). "Comparison of Static and Dynamic Backcalculation of Flexible Pavement Layer Moduli, using four Software Programs." Asian Journal of Applied Sciences, 2(3), pp. 197-210.

ANSYS Users’ Manual, ANSYS Inc., Cannonsburg, PA, 2002.

Barenberg, E. J. and Petros, K. A. (1991). "Final Summary Report Evaluation of Concrete Pavements using NDT Results.” Report No. FHWA/IL/UI 233.

Bhattacharya, K. (2000). "Nonlinear Response of Transverse Joints of Airfield Pavements." J. of Transportation Engineering, ASCE, 126(2), 168-177.

Chatti, K. and Kim, T. K. (2001). "Simple Dynamic Backcalculation Procedure for Falling Weight Deflectometer Testing of Rigid Pavement." Transportation Research Record, TRB, National Research Council, Washington D.C., 1764, pp. 30-38. 
Choudhary, N. K., Kumar, A., Kumar, Y. and Gupta, R. (2002). "Evaluation of Elastic Moduli of Concrete by Ultrasonic Velocity." NDE 2002 Predict, Assure, Improve, National Seminar of ISNT, Chennai.

Christory, J. P. (1988). "Evaluation of Concrete Pavements". Concrete Pavements, A. F. Stock, ed., Elsevier Applied Science, London.

Colley, B.E. And Humphrey, H.M. (1967). "Aggregate Interlock at Joints in Concrete Pavements." Bulletin 189, Highway Research Board. National Research Council, Washington D.C., pp. 1-18.

Crovetti, J. A. (2002). "Deflection-Based Analysis Techniques for jointed Concrete pavement Systems." Transportation Research Record, TRB, National Research Council, Washington D.C., 1809, pp. 3-11.

Davids, W. G., Wang, Z., Turkiyyah, G., Mahoney, J. P., and Bush, D. (2003). "Three-Dimensional Finite Element Analysis of Jointed Plain Concrete pavement with EverFE2.2." Transportation Research Record, TRB, National Research Council, Washington D.C., 1853, 92-117.

Fwa, T. F. and Setiadji, B. H. (2006). "Evaluation of Backcalculation Methods for Nondestructive Determination of Concrete Pavement Properties." Transportation Research Record, TRB, National Research Council, Washington D.C., 1949, pp. 8397.

Gambhir, M. L. (2004). "Concrete Technology.” Third Edition. Tata McGraw-Hill, New Delhi.

Guo, H., Sherwood, J.A. and Snyder, M.B. (1995). "Component Dowel-Bar Model for Load Transfer Systems in PCC Pavements." J. of Transportation Engineering, ASCE, 121(3), pp. 289-298.

Ioannides, A. M., Alexander, D.R., Hammons, M. I. and Davis, C. M. (2005). "Application of Artificial Neural Networks to Concrete Pavement Joint Evaluation." Transportation Research Record, Transportation Research Board, National Research Council, Washinton, D.C., 1540, 56-64.

IRC: 58 (2011). "Guidelines for the Design of Plain Jointed Rigid Pavements for Highways." The Indian Roads Congress, New Delhi.

Kanta Rao, V. V. L., Rao, M. V. B., Kumar, S. And Pokhriyal, S. P. (2006). "Structural Evaluation of Cement Concrete Roads in Mumbai City." J. of Performance of Constructed Facilities, ASCE, 20(2), pp. 156-166.

Li, S., and T. D. White. (2000). "Falling-Weight Deflectometer Sensor Location in the Backcalculation of Concrete Pavement Moduli." Journal of Testing and Evaluation, 28, (3), pp. 166-175.

Lin, D. F., Liau, C. C. and Lin, J. D. (2006). "Factors Affecting Portable Falling Weight Deflectometer Measurements." Journal of Geotechnical and Geoenvironmental Engineering, ASCE, 132(6), pp. 804-808. 
Maitra, S. R., Reddy, K. S. and Ramachandra, L. S. (2009a). "Experimental Evaluation of Interface Friction and Study of its Influence on Concrete Pavement response." J. of Transportation Engineering, ASCE, 135(8), pp. 563-571.

Maitra, S. R., Reddy, K. S. and Ramachandra, L. S. (2009b). "Load Transfer Characteristics of Dowel Bar System in Jointed Concrete Pavement." J. of Transportation Engineering, ASCE, 135(11), pp. 813-821.

Maitra, S. R., Reddy, K. S. and Ramachandra, L. S. (2010). "Load Transfer Characteristics of Aggregate Interlocking in Concrete Pavement." J. of Transportation Engineering, ASCE, 136 (3), pp. 190-195.

Neville, A. M. and Brookes, J. J. (1987). "Concrete Technology.” Longman Scientific \& Technical, John Wiley \& Sons, New York.

Picoux, B., Ayadi, A. El and Petit, C. (2009). "Dynamic Response of a Flexible Pavement Submitted by Impulsive Loading." Soil Dynamics and Earthquake Engineering, 29, pp. 845-854.

Reddy, M. A., Kumar, M. S., Reddy, K. S. and Pandey, B. B. (2003). "A Low Cost Falling Weight Deflectometer for Pavement Evaluation in India." International Journal of Pavement Engineering \& Asphalt Technology. UK, 4.

Rowe, G. M., Chang, K. G. and Tabrizi, K. (1997). "Use of the Falling Weight Deflectometer in conjunction with the Photographic Survey Methods in Concrete Pavement Restoration Program." Infrastructure Condition Assessment: Art, Science and Practice, M. Satio, ed., American Society of Civil Engineers, New York.

Shoukry, S. N. and William, G. W. (1999). "Performance Evaluation of Backcalculation Algorithms through Three-Dimensional Finite Element Modeling of Pavement Structures." Transportation Research Record, TRB, National Research Council, Washington D.C., 1655, pp. 152-160.

Shuo, L., Fwa, T. F. and Tan, K. H. (1997). "Back-Calculation of Parameters for Slab on Two-Layer Foundation System." Journal of Transportation Engineering, ASCE, 123(6), pp. 484-488.

Tang, B. (1993). "Structural Evaluation of Airfield Rigid Pavements Using Falling Weight Deflectometer." Journal of Transportation Engineering, ASCE, 119(3), pp. 467-476.

Westergaard, H.M. (1926). "Stresses in Concrete Pavements Computed by Theoretical Analysis." Public Roads, 7, pp. 25-35.

Yoder and Witczak (1975). Principles of Pavement Design. Second Edition, A WileyInterscience Publication, John Wiley \& Sons, Inc.

Zube, E. and Forsynth, R. (1966). "Evaluation of Pavements by Deflection Studies for Maintenance Purposes." Highway Research Record, No. 129, Highway Research Board, National Research Council, Washington D.C., pp. 60-75. 